\title{
Investigation on the Effects of Mathematics Professional Learning Community for Remedial Instruction
}

\author{
Yuan-Horng Lin ${ }^{1, ~ *, ~ T z u-T a ~ Y i u ~}{ }^{2}$, Jinn-Min Yang ${ }^{1}$ \\ ${ }^{1}$ Department of Mathematics Education, National Taichung University of Education, Taichung City, Taiwan \\ ${ }^{2}$ Department of Education, National Taichung University of Education, Taichung City, Taiwan
}

Email address:

lyh@mail.ntcu.edu.tw (Yuan-Horng Lin), yiu@mail.ntcu.edu.tw (Tzu-Ta Yiu), jinnminyang@mail.ntcu.edu.tw (Jinn-Min Yang)

${ }^{*}$ Corresponding author

\section{To cite this article:}

Yuan-Horng Lin, Tzu-Ta Yiu, Jinn-Min Yang. Investigation on the Effects of Mathematics Professional Learning Community for Remedial Instruction. Science Journal of Education. Vol. 5, No. 1, 2017, pp. 5-13. doi: 10.11648/j.sjedu.20170501.12

Received: December 18, 2016; Accepted: January 24, 2017; Published: February 10, 2017

\begin{abstract}
The purpose of study was to investigate the effects of mathematics professional learning community (PLC) for remedial instruction. The participant of the PLC was teachers from one primary school. They were invited to join the project of mathematics remedial instruction. This project was organized by the researcher who integrated components of effective mathematics instruction so as to help teachers carry out remedial mathematics instruction. The PLC teachers in the research are primary school teachers of fourth grade in Taiwan. In order to promote their knowledge of mathematics remedial instruction, they were engaged in the workshops of lesson studies and organized as school-based professional learning community. Lesson studies consisted of components to improve effectively remedial mathematics instruction. These components included life mathematics, scaffolding for mathematics reading comprehension, strategies for problem solving, guidance of representation and schema-based instruction. All the resources and instruction materials were established in the knowledge management platform in which teachers could access and share the resources. This longitudinal study was held for one year. The students of these PLC teachers took three waves of mathematics assessments so as to detect the effects of mathematics professional learning community. Results showed these students' mathematics achievement improves gradually. It was concluded that workshops of mathematical pedagogical content knowledge and establishment of knowledge management platform could help teachers for mathematics instruction. Finally, based on the findings, some suggestions for practical instruction and further research were also discussed.
\end{abstract}

Keywords: Knowledge Management Platform, Mathematical Pedagogical Content Knowledge, Remedial Instruction

\section{Introduction}

The purpose of this study aimed to investigate the effects of mathematics professional learning community (PLC) for remedial instruction. Many literatures found students had learning difficulties in mathematics and therefore they showed low mathematics achievement. Mathematics remedial instruction was essential to help those students who had lower achievement. Effective instruction which monitored assessments and multitiered instruction was the prerequisite of mathematics remedial instruction [7]. Strategies of mathematics instruction were an important issue in mathematics education. One purpose of efficient strategies aimed to improve students' understanding and reasoning of mathematics concepts. There were many characteristics of effective mathematics lessons. These characteristics included well development of the concepts or skills, suitable guided practice and discovery. Mathematical pedagogical content knowledge was the key factor that influenced effective mathematic instruction [1].

Mathematical pedagogical content knowledge of teachers was necessary for effective instruction since mathematics achievement of students is also largely attributed to teachers' instruction and knowledge [15]. Mathematics remedial instruction required specific instruction strategies so as to promote students' attitude and achievement. Those instruction strategies included schema-based strategy, suitable representation to improve mathematics 
understanding and real word context in mathematics problems. However, many teachers needed those professional developments for mathematics remedial instruction.

Since the late 1990s, many literatures on PLC had been published. PLC Professional learning community (PLC) was a method to foster constructive and collaborative learning among colleagues within supportive environment [6]. It indicated that PLC encouraged providing the setting and the working relationships demanded of constructivist learning. There were six research-based dimensions of PLC and they were [5]:

- Shared beliefs, values, and a vision of what the school should be;

- Shared and supportive leadership where power, authority, and decision-making are distributed across the community;

- Supportive structural conditions, such as time, place, and resources;

- Supportive relational conditions that include respect and caring among the community, with trust as an imperative;

- Collective learning, intentionally determined, to address student needs and the increased effectiveness of the professionals;

- Peers sharing their practice to gain feedback, and thus individual and organizational improvement.

PLC was often used in schools as a way to organize teachers into practice-based professional learning groups. Besides, PLC has been also considered as the activity to improve teachers' professional competency and students' achievement. It was indicated the essential characteristics of professional learning communities in schools included many dimensions [2]. They were: (1) shared values and norms around "views about children and children's ability to learn, school priorities for the use of time and space, and the proper roles of parents, teachers, and administrators; (2) a focus on student achievement; (3) reflective dialogue among teachers on curriculum, instruction and student development; (4) making teaching a public rather than a private venture; and (5) collaboration among colleagues.

According to most researches, teachers need more mathematical pedagogical content knowledge for remedial instruction and know how to adopt proper teaching strategies. Therefore, professional development activities for mathematics teachers appear to be a prospective research. Based on the discussions above, it was prospective to organize PLC and promote teachers' mathematical pedagogical content knowledge for remedial instruction. Therefore, this study attempted to organize mathematics PLC and help teachers adopt effective strategies for mathematics remedial instruction. Results of mathematics assessment for students will be analyzed.

\section{Literature Review}

This study was to promote primary school teachers' mathematics pedagogical content knowledge for remedial instruction. The teachers were organized as PLC so as to improve their knowledge and resource for mathematics instruction. Mathematics assessment of students was analyzed to detect the effects. The theoretical foundation and related researches would be discussed as follows.

\subsection{Mathematical Pedagogical Content Knowledge for Remedial Instruction}

Many literatures indicated mathematics teachers should have special kind knowledge for mathematics instruction. Pedagogical content knowledge only existed but also contributes to effective instruction [14]. Quite a few researches investigated effects of teachers' mathematical knowledge for teaching on student achievement [15]. Many on them indicated that teachers' mathematical knowledge was significantly related to student achievement gains after controlling for key student- and teacher-level covariates. This finding provided suggestions to improve students' mathematics achievement by improving teachers' mathematical knowledge. It was found that teachers' mathematics pedagogical content knowledge is apparently the most important factor to students' achievement [15]. The concept of pedagogical content knowledge could be refined as five subcomponents. They included knowledge of alternative content frameworks, knowledge of student understanding and misconceptions, knowledge of curriculum, knowledge of particular content for teaching, and knowledge of topic specific pedagogical strategies [30].

As to knowledge for instruction, it was proposed three types of subject matter knowledge (SMK) and three types of pedagogical content knowledge (PCK). As shown in Figure 1, the categorized knowledge is non-overlapping and each category owned its special meaning for teaching. It was shown in Figure 1 [33].

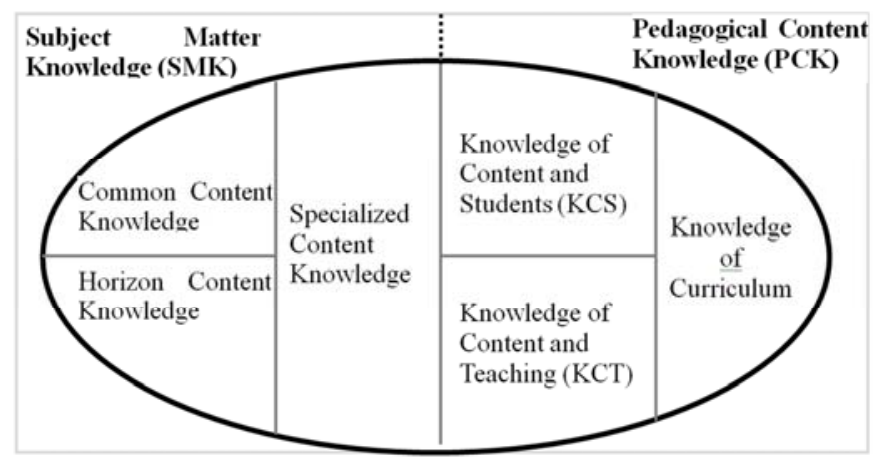

Figure 1. Dimensions of knowledge for teaching (Hill, Ball, and Schilling (2008).

Teachers' knowledge was related to individual experiences and contexts. A major conclusion from literature was that understanding and improvement of teachers' mathematics instructional knowledge may be useful to promote teacher professional development and to make remedial instruction more successful.

The content and the way for mathematics remedial instruction were a big issue in recent years. Viewpoints of 
learning mathematics for lower achievement students often emphasized the process in which students construct their concepts and knowledge by engaging in meaningful and purposeful activities [16]. Besides, many researches also indicated the close relationships between teachers' mathematics pedagogical knowledge and students' mathematics learning. It revealed the role of teachers' mathematics instructional knowledge in their classroom was important. For example, many researches pointed out that mathematics instruction often could not afford to address the needs of students of learning difficulties. Mathematics remedial instruction for students of learning difficulties required suitable materials and efficient strategies [17]. Usage of representation and schema linkage could help students construct mathematics concepts. Scaffolding offered students support to improve learning and problem solving. Moreover, real-life mathematics context was appropriate for linking concrete experiences and abstract concepts [18] [19]. All the mentioned above would benefit mathematics remedial instruction.

Daily experiences were the foundations of concept construction. For those students who needed remedial instruction, mathematics textbooks often lacked real-life experiences which resulted in learning difficulties.
Mathematics classes sometimes ignored the authentic proficiency needed in real life. The real-life mathematics knowledge was essential in their social community and pursuing advanced knowledge. Many researchers investigated the effectiveness of realistic mathematics education (RME) in classroom so as to analyze its influence on mathematics belief, problem solving abilities, and mathematics representation. It revealed that there existed positive effects of RME on mathematics proficiency [20]. Mathematics understanding often happened based on the life experiences. Furthermore, application of realistic mathematics education (RME) in the intervention of assisting low attaining learners showed the positive effects for those students. Namely, real-life mathematics merged in the mathematics classroom will be helpful for remedial instruction.

In mathematics classroom, teachers were an active role not only in facilitating the acquisition of new mathematics concepts by their students, but also in providing pedagogical experiences that may help students extend the concepts into new territories [21]. Literature had provided a structural framework for teachers' mathematical knowledge and modeling of a focus concept. The framework was shown in Figure 2 [21].

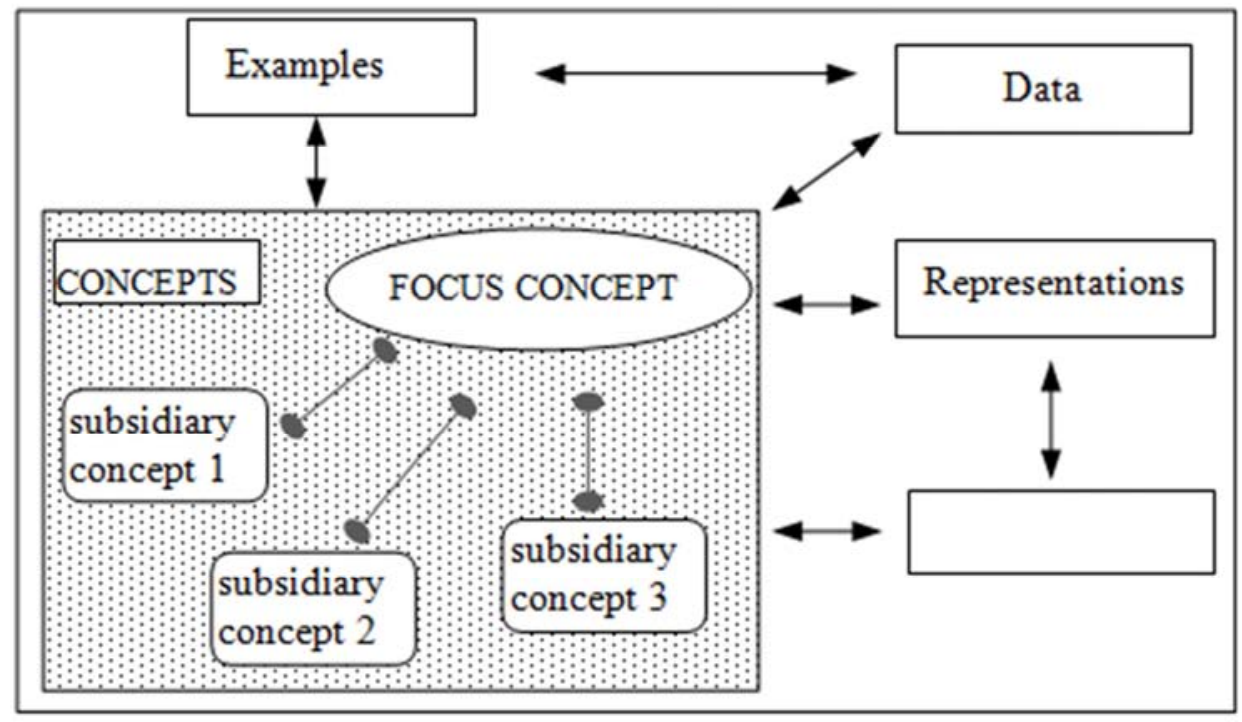

Figure 2. Structural framework for teachers' mathematical knowledge and modeling of a focus concept (Chinnappan \& Thomas, 2003).

Mathematics instruction with schema was also considered as useful strategies for students with learning disabilities [29]. Students of lower mathematics achievement needed refined assimilation and accommodation in schema connection when learning mathematics [22]. Schema-based strategy instruction (SBI) emphasized meaningful representation to help students understand problems and construct knowledge. The SBI strategy was effective because it supported students specific strategies for word problems. SBI could increase conceptual understanding and procedural understanding of word-problem-solving for students. There existed positive effects of schema-based instruction in helping students with learning disabilities of mathematics [28]. The adapted multiple-probe-across-participants design was also employed to evaluate the functional relation between the schema-based instruction and students' performance in mathematical word problems. Results demonstrated the effectiveness for students of low mathematics achievement.

Mathematical representation was permanently considered as one of the influential factors to influence problem solving. One was concluded that the concrete-representationalabstract (CRA) instructional sequence was better than representational-abstract (RA) instructional sequence for remedial instruction [25].

It was an essential aspect of instruction mathematics to develop the language of mathematics in classroom. There 
were many challenges for students to understand the language of mathematics. It also revealed there were at least 11 categories of difficulties associated with learning mathematical language [23]. These categories were: (1) the meanings were context dependence; (2) mathematical meanings were more precise; (3) the terms were specific to mathematical contexts; (4) there existed multiple meanings; (5) there existed discipline-specific technical meanings; (6) there were homonyms with everyday words; (7) there were related but different words; (8) students had specific challenges with translated words; (9) there existed irregularities in spelling; (10) mathematical concepts may be verbalized in many ways; (11) students and teachers may adopt informal terms instead of mathematical terms.

Some literature reconsidered the importance of mathematical vocabulary and language in classroom [24]. They concluded the viewpoints from R. J. Marzano and provided the concept map for effective mathematical vocabulary instruction. The concept map was as shown in Figure 3.

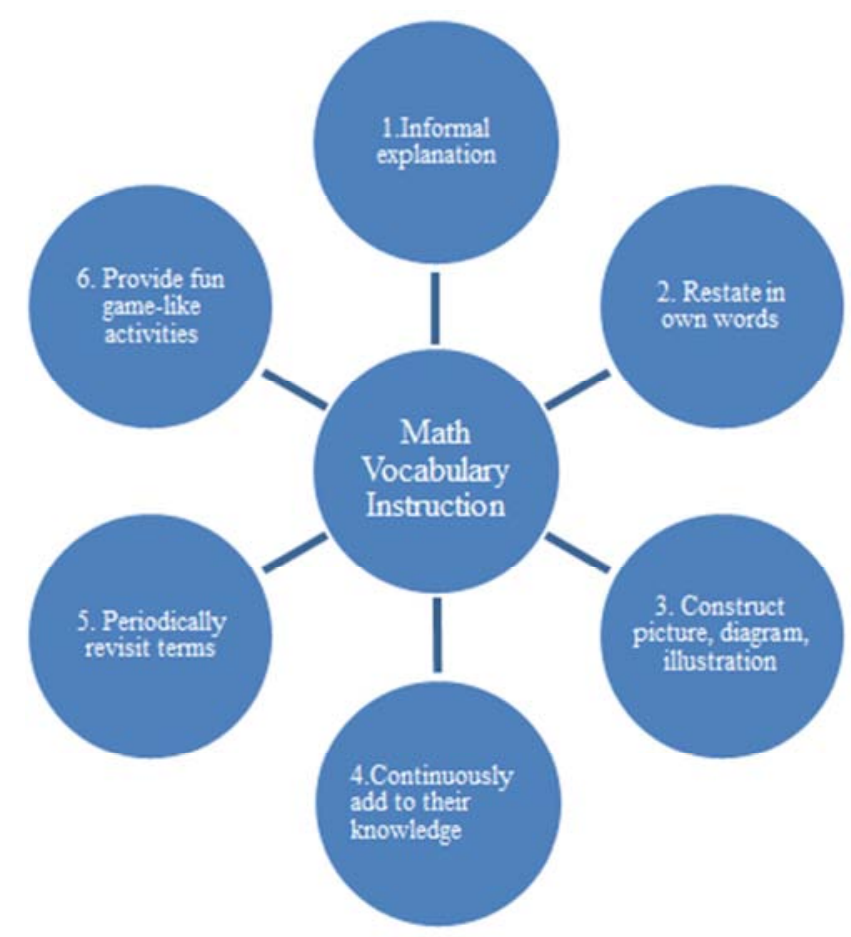

Figure 3. The concept map for effective mathematical vocabulary instruction (Riccomini, Smith, Hughes, \& Fries, 2015).

Mathematical language in classroom was considered as one important aspect of mathematics communication. Mathematical language was also addressed in the Principles and Standards for School Mathematics (NCTM 2000). Students should use precise mathematical language for communication in classroom. They must develop an appreciation for precise definitions and for the communicative power of mathematical terms in their own words [27]. Teachers also must guide them in doing so. Students who needed remedial mathematics instruction required more connection between life language and formal mathematical language

It showed that mathematical schema and representation decided the comprehension of mathematical language in problem solving [26]. The transformation to reform mathematics teaching was a daunting task because teachers needed to realize what such a classroom would really look like [11]. They generated developmental trajectories for teacher and student learning which described the building of a math-talk learning community. The math-talk learning community framework included four components. They were (a) questioning, (b) explaining mathematical thinking, (c) sources of mathematical ideas, and (d) responsibility for learning. In accordance with this point, it revealed that adaptive math-talk in classrooms should be importance for remedial instruction.

According to the viewpoints discussed above, this study will integrate these effective components of remedial instruction and help primary school teachers promote mathematical pedagogical content knowledge.

\subsection{Mathematics Instruction and Professional Learning Community (PLC)}

The 2005 report by the Ontario Ministry of Education titled "Education for All" mentioned that the characteristics of PLC were as follows.

- Shared vision and values that lead to commitment of school staff

- Solutions are open to new ideas

- Working teams cooperate together for common goals

- Encouragement of experimentation as an opportunity to learn

- Questioning of the status which leads to improvement and professional learning

- Continuous improvement based on evaluation of outcomes

- Reflection in order to study the operation and actions

As to PLC in schools, there were three big ideas to represent the core principles. It was depicted in Table 1 [9].

Table 1. Three big ideas of PLC schools.

\begin{tabular}{ll}
\hline Big ideas & Descriptions \\
\hline $\begin{array}{l}\text { Big Idea \#1 Ensuring } \\
\text { That Students Learn }\end{array}$ & $\begin{array}{l}\text { The core mission of formal education is not } \\
\text { simply to ensure that students are taught but to } \\
\text { ensure that they learn. }\end{array}$ \\
$\begin{array}{l}\text { Big Idea \#2 A } \\
\text { Culture of } \\
\text { Collaboration }\end{array}$ & $\begin{array}{l}\text { Educators must work together to achieve their } \\
\text { collective purpose of learning for all. }\end{array}$ \\
$\begin{array}{l}\text { Big Idea \#3 } \\
\text { A Focus on Results }\end{array}$ & $\begin{array}{l}\text { Professional learning communities work together } \\
\text { to improve student achievement becomes the } \\
\text { routine work of everyone in the school. }\end{array}$ \\
\hline
\end{tabular}

Lesson study community was also one way of PLC. Lesson study was the teaching improvement process that had origins in Japanese elementary education and now it was a widespread professional development practice. Lesson study helped teachers collaborate with one another and plan actual classroom lessons. Peers observed how their ideas work in a live lessons with students [8]. 
Many research attempted to access mathematics teachers' lenses in order to explore their views on the effects of subject-based professional learning activities [3]. It investigated how mathematics teachers worked and openly shared their practices so as to improve their professional competency and students' achievement within their communities. It was found that there were positive effects of PLC and influential factors for the sustainability of the mathematics PLC.

It was prospective to explore the use of classroom video as a tool for fostering productive discussions about teaching and learning. Mathematics professional development program based on the problem-solving cycle model was considered one way of establishment for PLC [4]. It emphasized creating a community in which members feel comfortable learning from video. In the PLC, the teacher did efforts to promote a supportive and analytical environment. The peers interaction within PLC provided positive effects on professional development.

In 2003, Ontario Ministry of Education indicated that an effective mathematics learning environment was a community of learners who feel that their knowledge and thoughts were valued, who felt safe in trying to solve problems and who were comfortable talking about understanding of mathematics [10]. Its important components were shown in Figure 4.

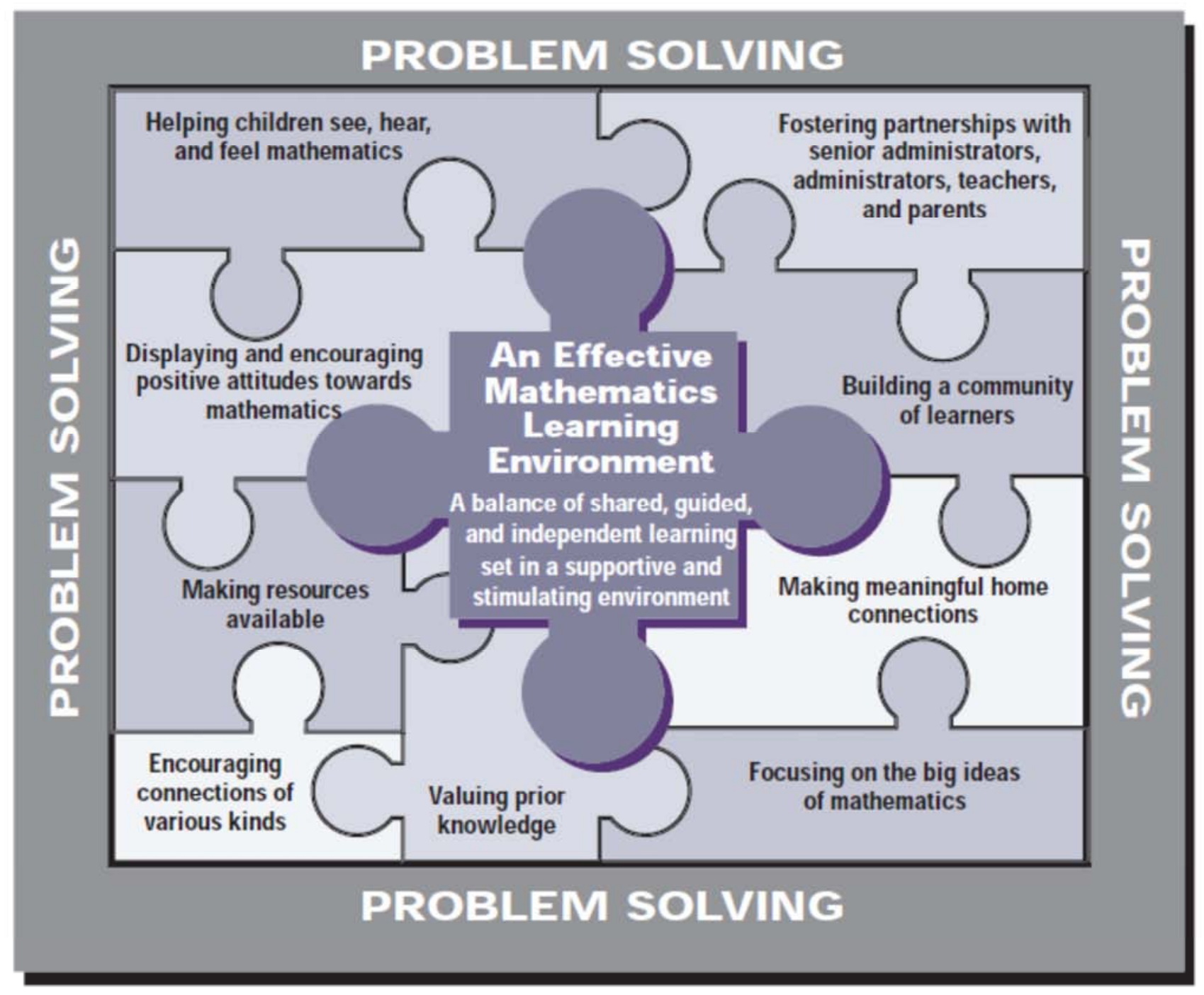

Figure 4. The components of an effective mathematics learning environment (Ontario Ministry of Education, 2003, p. 12).

The school-based professional community entailed works that made teachers' classroom public for examination by colleagues or consultants [12]. It also brought critical dialogue about classroom practices and collaboration among teachers that focused on strengthening the school's instructional activities.

It was essential to investigate the relationship between PLC activities and teacher improvement in schools. According to the professional development survey, teacher interviews, and a review of school documents, it demonstrated that PLC activities had the potential to achieve significant improvements in teaching effectiveness [13]. Besides, the effectiveness relied on leadership and organizational practices, the PLC activity and conversations. 
Technology was one efficient tool to promote teachers' professional knowledge. The common components of teachers' knowledge included four categories of knowledge, which were knowledge of content, context specific knowledge, pedagogical knowledge, and knowledge of learners' cognition. These four components of teachers' knowledge would influence each another. It was considered the development of technology had influenced the usage in educational environment. The concept of technological and pedagogical content knowledge was discussed. Their relationships were shown in Figure 5 [31].

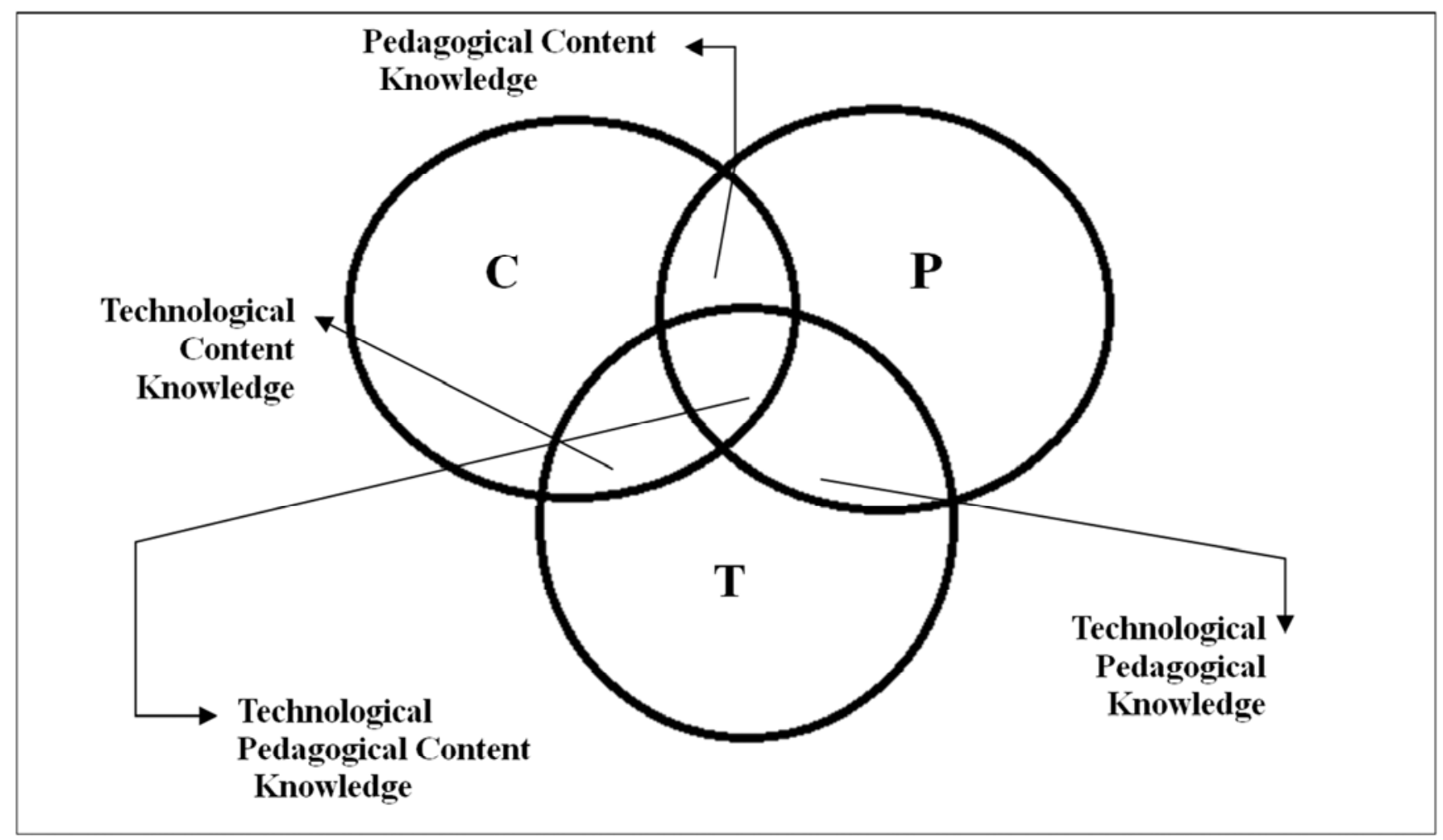

Figure 5. The structure among content, pedagogy and technology (Mishra \& Koehler, 2006, p.1025).

STEM (science, technology, engineering, and mathematics) was an educational program developed to prepare students studying in the fields of STEM. In addition to subject learning, STEM aimed to foster inquiring minds, logical reasoning, and collaboration skills. STEM teaching was more effective and student achievement increased when teachers developed professional learning communities in mathematics instruction and technological media to share their knowledge [32]. In the STEM approach of PLC, The knowledge synthesis could help STEM teachers improve their practice. The refined instruction included more use of student inquiry. Teachers paid more attention to students' reasoning and understanding and more diverse modes of engaging students in mathematics problem solving.

\section{Research Design}

This study aimed to integrate components of effective mathematics instruction and hold school-based professional learning community (PLC) workshop for teachers so as to promote knowledge of mathematics remedial instruction. This longitudinal study lasted for one year. The students of these PLC teachers took three mathematics assessments. Their mathematics performance was discussed so as to detect the effects of mathematics professional learning community.

\subsection{Participants}

The PLC teachers in the research were four primary school teachers from one primary school. This primary school was located at the Taichung city, Taiwan. These four teachers are mathematics teachers of four fourth grade classes respectively. As to each class, there are about twenty more students. The researchers of this paper and these four teachers organized PLC group.

\subsection{Design of Workshop}

Effective mathematics instruction was the prerequisite of remedial mathematics instruction. In this study, there were four components as to effective instruction. As shown in Figure 6, they were life mathematics in classroom, strategies for problem solving and mathematics reading comprehension, guidance of schema-based instruction and scaffolding. All the theoretical foundation and practical examples were scheduled in the workshops. From August 2014 to 2015 July, there were two joint workshops of three days. In addition, there were two workshops of two hours during each semester. In the workshop, teachers did lesson study with the researchers. 


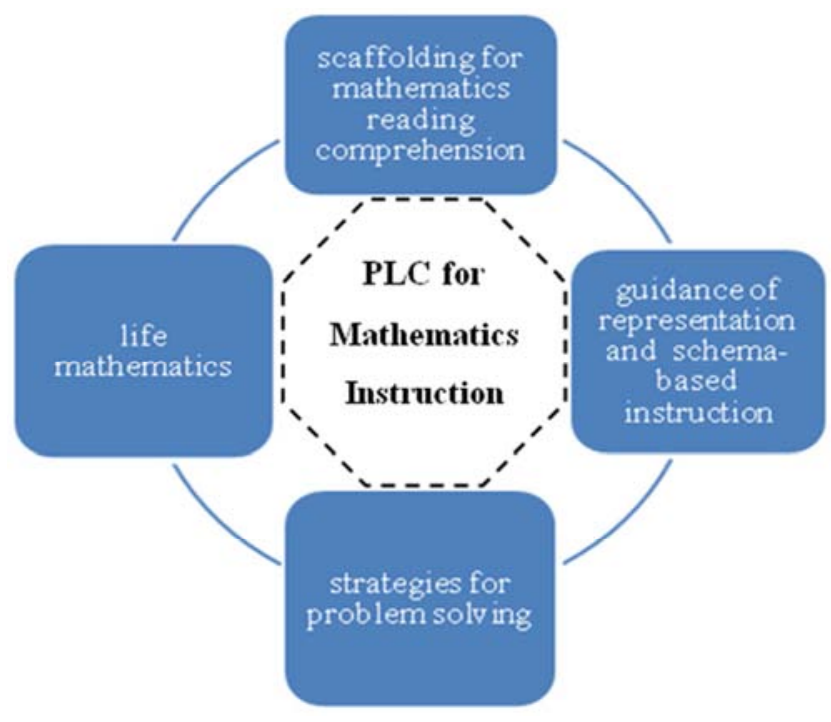

Figure 6. The components of PLC for mathematics instruction.

\subsection{Platform and Mathematics Assessment}

This study was a longitudinal design. All the resources for effective mathematics instruction were built in platform and teachers could login website so as to carry out effective mathematics instruction. When teachers login the platform, they can review and share the instructional resources. Teachers adopted these effective instruction strategies in their mathematics classroom. The researchers designed mathematics assessment and teachers could check the performance of their students from the platform. The sample size in accordance with each class was depicted in Table 2.

Table 2. Sample size of students.

\begin{tabular}{lll}
\hline Class & Number of students & Percent \\
\hline 1 & 21 & $24.1 \%$ \\
2 & 21 & $24.1 \%$ \\
3 & 22 & $25.3 \%$ \\
4 & 23 & $26.5 \%$ \\
Total & 87 & $100 \%$ \\
\hline
\end{tabular}

\section{Results and Discussions}

This research was one year term of longitudinal study. The teachers of all the participants were organized as professional learning community (PLC). They adopted and applied the strategies of effective mathematics instruction in the classroom. Their students took three mathematics assessments, which were hold in Jan. 2014., Mar. 2015 and Jun. 2015 respectively. These assessments were achievements and curriculum-based test to detect their performance.

\subsection{Statistical Description for Assessment}

As shown in Table 3 and Figure 7, mean of these three assessments gradually increased. Besides, the standard deviation became lower from assessment I to assessment III.
Table 3. The statistical description for.

\begin{tabular}{lll}
\hline Assessment & Mean & Standard deviation \\
\hline I & 68.73 & 19.169 \\
II & 68.95 & 19.316 \\
III & 77.40 & 16.533 \\
\hline
\end{tabular}

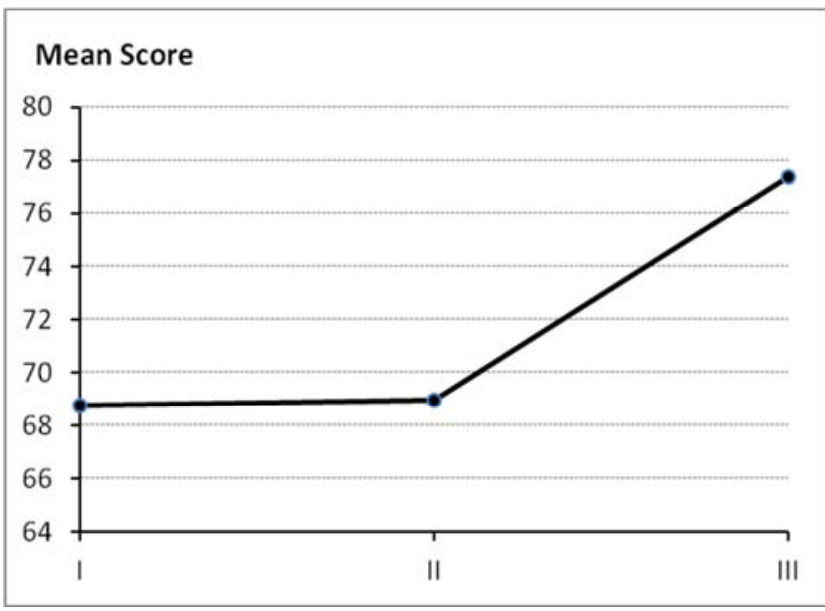

Figure 7. Line chart of cluster center for each dimension.

\subsection{Statistics Test for Mean Comparisons}

Multivariate statistics for repeated measure was adopted to analyze the longitudinal data. Scores of the three assessments were dependent variables. Statistics test showed that the Wilks' $\Lambda=0.661(\mathrm{~F}=25.096, \mathrm{p}<.001)$. It means there existed significant difference among the mean scores. Univariate statistics for mean comparisons was depicted as Table 4. It revealed that students' performance in assessment III was better than assessment I. Similarly, students' performance in assessment III was also better than assessment II.

Table 4. Mean comparisons among assessments.

\begin{tabular}{lll}
\hline Comparisons of assessment & Mean difference & t-test \\
\hline I- II & -0.22 & .899 \\
I- III & -8.67 & $-6.355^{* * *}$ \\
II- III & -8.45 & $--5.891 * * *$ \\
\hline
\end{tabular}

$* * * \mathrm{p}<.001$

According to the analyses and discussions above, one was concluded that the positive effects of PLC experiment on students' mathematics achievement.

\section{Conclusions}

This research aimed to improve teachers' professional development of mathematics instruction and help them organize professional learning community (PLC). By this way, teachers could adopt efficient strategies in their mathematics classroom. Results showed that students could perform better. This research gave practical evidence for the effective mathematics instruction strategies. Further studies could adopt quality method and analyze students' misconceptions and attitudes. 


\section{Acknowledgements}

This research was supported by Ministry of Science and Technology of Taiwan, R. O. C. under grant MOST 103-2511-S-142-024-MY3.

\section{References}

[1] Crawford, D. B., \& Snider, V. E. (2000). Effective mathematics instruction the importance of curriculum, Education and Treatment of Children, 23 (2), 122-142.

[2] Newman, F. M. \& Associates (Eds). (1996). Authentic instruction: Restructuring schools for intellectual quality. San Francisco: Jossey.

[3] Wong, J. L. (2010). What makes a professional learning community possible? A case study of a mathematics department in a junior secondary school of China. Asia Pacific Education Review, 11 (2), 131-139.

[4] Borko, H., Jacobs, J., Eiteljorg, E., \& Pittman, M. E. (2008). Video as a tool for fostering productive discussions in mathematics professional development. Teaching and teacher education, 24 (2), 417-436.

[5] Hord, S. M. (2009). Professional learning communities: Educators work together toward a shared purpose. Journal of Staff Development, 30 (1), 40-43.

[6] Myers, C. B. \& Myers, L. K. (1995). The professional educator: a new introduction to teaching and schools. Belmont, CA: Wadsworth Publishing.

[7] Fletcher, J. M., and Vaughn, S. (2009). Response to intervention: Preventing and remediating academic difficulties. Child Development Perspectives, 3 (1), 30-37.

[8] Hart, L. C., Alston, A., \& Murata, A. (2011). Lesson study research and practice in mathematics education. New York: Springer.

[9] DuFour, R. (2004). What is a professional learning community? Educational Leadership. 61 (8), 6-11.

[10] Ontario Ministry of Education. (2003). Early math strategy: The report of the expert panel on early math in Ontario. Toronto. Queen's Printer for Ontario.

[11] Hufferd-Ackles, K., Fuson, K. C., \& Sherin, M. G. (2004). Describing levels and components of a math-talk learning community. Journal for Research in Mathematics Education, $35,81-116$

[12] Bryk, A., Allensworth, E., Sebring, P., Luppescu, S., \& Easton, J. (2010). Organizing schools for improvement: Lessons from Chicago. Chicago: University of Chicago Press.

[13] Graham, P. (2007). Improving Teacher Effectiveness through Structured Collaboration: A Case Study of a Professional Learning Community. RMLE online, 31 (1), 1-17.

[14] Shulman, L. S. (1986). Those who understand: Knowledge growth in teaching. Educational Researcher, 15 (2), 4-14.

[15] Hill, H. C., Rowan, B., \& Ball, D. L. (2005). Effects of teachers' mathematical knowledge for teaching on student achievement. American Educational Research Journal, 42 (2), 371-406.
[16] Bottge, B. A., Heinrichs, M., Chan, S. Y., and Serlin, R. C. (2001). Anchoring adolescents' understanding of math concepts in rich problem-solving environments. Remedial and Special Education, 22, 299-314.

[17] Patton, J. R., Cronin, M. E., Bassett, D. S., and Koppel, A. E. (1997). A life skills approach to mathematics instruction preparing students with learning disabilities for the real-life math demands of adulthood. Journal of Learning Disabilities, 30 (2), 178-187.

[18] Jitendra, A. K., \& Star, J. R. (2011). Meeting the needs of students with learning disabilities in inclusive mathematics classrooms: The role of schema-based instruction on mathematical problem-solving. Theory into practice, 50 (1), 12-19.

[19] Ketterlin-Geller, L. R., Chard, D. J., \& Fien, H. (2008). Making connections in mathematics conceptual mathematics intervention for low-performing students. Remedial and Special Education, 29 (1), 33-45.

[20] Yuanita, P., and Zakaria, E. (2016). The effect of realistic mathematics education (RME) implementation to mathematics belief, mathematics representative and mathematics problem solving. Advanced Science Letters, 22, 1989-1992.

[21] Chinnappan, M., \& Thomas, M. (2003). Teachers' function schemas and their role in modelling. Mathematics Education Research Journal, 15 (2), 151-170.

[22] Jitendra, A., DiPipi, C. M., and Perron-Jones, N. (2002). An exploratory study of schema-based word-problem-solving instruction for middle school students with learning disabilities: An emphasis on conceptual and procedural understanding, The Journal of Special Education, 36 (1), 23-38.

[23] Rubenstein, R. N., \& Thompson, D. R. (2002). Understanding and support children's mathematical vocabulary development. Teaching Children Mathematics, 9 (2), 107-112.

[24] Riccomini, P. J., Smith, G. W., Hughes, E. M., \& Fries, K. M. (2015). The language of mathematics: The importance of teaching and learning mathematical vocabulary. Reading \& Writing Quarterly, 31 (3), 235-252.

[25] Butler, F. M., Miller, S. P., Crehan, K., Babbitt, B., and Pierce, T. (2003). Fraction instruction for students with mathematics disabilities: Comparing two teaching sequences. Learning Disabilities Research \& Practice, 18 (2), 99-111.

[26] Rudd, L. C., Lambert, M. C., Satterwhite, M., and Zaier, A. (2008). Mathematical language in early childhood settings: What really counts? Early Childhood Education Journal, 36 (1), 75-80.

[27] Herbel-Eisenmann, B. A. (2002). Using student contributions and multiple representations to develop mathematical language. Mathematics Teaching in the Middle School, 8 (2), 100-105.

[28] Xin, Y. P. (2008). The effect of schema-based instruction in solving mathematics word problems: An emphasis on prealgebraic conceptualization of multiplicative relations. Journal for Research in Mathematics Education, 39, 526-551.

[29] Milo, B. F., Seegers, G., Ruijssenaars, W. A., and Vermeer, H. J. (2004). Affective consequences of mathematics instruction for students with special needs. European Journal of Special Needs Education, 19, 49-68. 
[30] Shulman, L. S., \& Grossman, P. L. (1988). Knowledge growth in teaching: A final report to the spencer foundation. Stanford, CA: Standford University.

[31] Mishra, P., \& Koehler, M. (2006). Technological pedagogical content knowledge: A framework for teacher knowledge. The Teachers College Record, 108 (6), 1017-1054.

[32] Fulton, K., \& Britton, T. (2011). STEM teachers in professional learning communities: from good teachers to great teaching. National Commission on Teaching and America's Future.

[33] Hill, H. C., Ball, D. L., \& Schilling, S. G. (2008). Unpacking pedagogical content knowledge: Conceptualizing and measuring teachers' topic-specific knowledge of students. Journal for Research in Mathematics Education, 39, 372-400. 